ANUARIO DE ESTUdios MEDIEVALES

50/1, enero-junio de 2020, pp. 353-381

ISSN 0066-5061

https://doi.org/10.3989/aem.2020.50.1.13

\title{
CRÉDITO, ACREEDORES Y DEUDORES EN UN PUEBLO CASTELLANO: CASTRILLO TEJERIEGO (1334-1335)*
}

\author{
CREDIT, CREDITORS AND DEBTORS IN A CASTILIAN VILLAGE: \\ CASTRILLO TEJERIEGO (1334-1335)
}

\author{
Carlos Manuel Reglero de la Fuente \\ Universidad de Valladolid \\ https://orcid.org/0000-0002-3361-1815
}

\begin{abstract}
Resumen: El registro notarial de Castrillo Tejeriego permite conocer el crédito en un pueblo castellano en 1334-1335, coincidiendo con una importante carestía. Domina la forma más sencilla de deuda, el mutuum, aunque también hay noticias del commodatum. Se trata fundamentalmente de deudas entre cristianos, a corto plazo, que se pagan con la nueva cosecha. La mayoría están ligadas a ventas a crédito de alimentos, pero también derivan de la compra de tierras, de arrendamientos o del pago de tributos. Los principales acreedores, al margen del señor del lugar, comerciaban con cereal, mientras que entre los deudores figura un variado elenco de clérigos y campesinos, de muy diversa solvencia. Las deudas muestran además la solidaridad familiar y vecinal a través de préstamos, fianzas y mancomunados.
\end{abstract}

Palabras clave: crédito; acreedor; deudor; Castilla; siglo XIV; campesinado; carestía.

Abstract: The notary's register of Castrillo Tejeriego sheds light on credit in a Castilian village in 1334-1335, during a period of serious food shortages. The most common form of debt was the $m u$ tuum, which was also the simplest, although there is also evidence of commodatum. The debts were mainly short-term ones between Christians, which were paid off with the next harvest. Most were connected with food bought on credit, but some also arose from the purchase of land, rents or tax payments. The main creditors, apart from the local lord, traded in cereals, while the debtors ranged from clerics to peasants of varying degrees of solvency. The debts also demonstrate the solidarity existing between relatives and neighbours through loans, guarantors and joint liability.

Keywords: credit; creditor; debtor, Castile; $14^{\text {th }}$ century; peasantry; shortages.

\section{SUMARIO}

1. La fuente: posibilidades y límites para el estudio del crédito rural.- 2. El contexto espacial y temporal.- 3. El crédito y sus fórmulas legales.- 3.1. El mutuum: un reconocimiento de deuda.- 3.2. El commodatum: el usufructo de la heredad como interés.- 4. Beneficios y garantías del préstamo.- 5. El objeto del préstamo y los plazos de devolución.- 5.1. La dimensión temporal del crédito.- 5.2. Préstamos en cereal y préstamos en dinero.- 6. Los acreedores.- 7. Los deudores.- 7.1. El impago de la deuda.7.2. La acumulación de deudas y su significado.- 8. Dos casos singulares.- 8.1. Las deudas del concejo.- 8.2. El crédito judío.- 9. Conclusiones.- 10. Bibliografía citada.

\footnotetext{
* Trabajo realizado dentro del proyecto de investigación El ejercicio del poder: espacios, agentes y escrituras (siglos $X I-X V)$ (HAR2017-84718-P), financiado por MICINN/AEI/UE-FEDER.

Citation / Cómo citar este artículo: Reglero de la Fuente, Carlos Manuel (2020), Crédito, acreedores y deudores en un pueblo castellano: Castrillo Tejeriego (1334-1335), “Anuario de Estudios Medievales” 50/1, pp. 353-381. https://doi. org/10.3989/aem.2020.50.1.13

Copyright: (C) 2020 CSIC. Este es un artículo de acceso abierto distribuido bajo los términos de la licencia de uso y distribución Creative Commons Reconocimiento 4.0 Internacional (CC BY 4.0).
} 
El estudio del crédito rural en la Edad Media ha suscitado gran interés, tanto en el mundo urbano como en el rural. Han quedado atrás los tópicos que lo focalizaban en el préstamo de los judíos, con intereses usurarios, y se han abierto nuevas perspectivas de análisis, en las que se destaca su papel de dinamizador económico y la complejidad social del mundo de acreedores y deudores. En el ámbito español destaca la síntesis realizada por Furió, asî como los trabajos sobre la Corona de Aragón, en especial el de García Marsilla $^{1}$. En el caso castellano, la escasez de documentación notarial y judicial hasta fines del siglo XV hace que los trabajos se centren en los últimos años de la Edad Media, con la notable excepción de Castán Lanaspa, cuyo artículo muestra los límites impuestos por las fuentes².

Este trabajo se propone mostrar la difusión del crédito en el mundo campesino castellano en la primera mitad del siglo XIV, a través del ejemplo de Castrillo Tejeriego (Valladolid). Más que una cuantificación del crédito, se centra en las modalidades que este adopta y, en especial, en el mundo de los acreedores y deudores, de sus necesidades y actuación en un espacio y tiempo muy concreto, los años 1334-1335.

\section{LA FUENTE: POSIBILIDADES Y LÍMITES PARA EL ESTUDIO DEL CRÉDITO RURAL}

El registro del escribano Gonzalo Pérez de Castrillo Tejeriego (Valladolid) contiene 165 notas entre el 28 de enero de 1334 y el 7 de mayo de 1335 . Se trata del registro notarial más antiguo conocido, hasta el momento, en la Corona de Castilla, y abre una nueva ventana al mundo rural castellano de la primera mitad del siglo XIV . Algo más de la mitad de sus notas están relacionadas, directa o indirectamente, con una deuda, superando ampliamente a las ventas, que suponen cerca de la tercera parte. Así, se registraron 69 reconocimientos de deuda, bajo la forma más sencilla de crédito, el mutuum, y dos dentro de un contrato de arrendamiento. Otros 23 documentos se refieren a una deuda o fianza.

El volumen de documentación es importante dentro de las escasas noticias de la documentación castellana de la primera mitad del siglo XIV.

\footnotetext{
${ }^{1}$ Furió 1998; García 2002; Fernández 1998; Sánchez 2007; Soldevila 2008; Laliena, Iranzo 2016; Carrasco 2008.

${ }^{2}$ Castán 1983; Borrero 1986, 2006; Ladero 1990-1991; Casado 1987, pp. 530-535; Carvajal 2013.

${ }^{3}$ El registro se encuentra recogido en un pleito: Archivo de la Real Chancillería de Valladolid, Pleitos Civiles, Varela, Fenecidos, caja 941/1. Está en preparación su edición y estudio por parte de Mauricio Herrero y mía. En la misma se desarrollarán muchos más temas que en este artículo: la economía y sociedad rural, las relaciones de poder, etc.
} 
No obstante, resulta reducido en comparación con las cifras manejadas para Cataluña o Valencia en estas mismas fechas, donde se analizan miles de operaciones de préstamos ${ }^{4}$. Por otra parte, no recoge la totalidad de operaciones de crédito del lugar. Aunque no hay noticia de otro notario en Castrillo, sus moradores también registraron deudas ante escribanos de Valladolid (se mencionan dos casos) o con un judío de Peñafiel. Además, como en Cataluña o Valencia, parte de las deudas no eran registradas ante notario, y sólo hay noticia cuando se reclaman ante los alcaldes. Todo ello lleva a ser muy prudentes a la hora de ofrecer cifras e interpretar los datos.

\section{EL CONTEXTO ESPACIAL Y TEMPORAL}

A mediados del siglo XIV Castrillo Tejeriego pertenecía a la merindad del Infantado de Valladolid. El Becerro de las Behetrías (1352) indica que era señorío del obispo de Osma (sede episcopal sita a más de 120 km.), quien recibía de cada vasallo un yantar, un pecho y seis sernas cada año. Estas últimas las realizaban solo los "pecheros mayores", a quienes correspondía un pecho de $8 \mathrm{mrs}$. y un yantar de 72, reduciéndose en aquellos que tenían menos recursos. A ello se añadía una especie de martiniega (nueve sueldos del pechero mayor y cuatro de los medianos). Estaban exentos de fonsadera, yantar al rey u otro cualquiera, por lo que los únicos derechos reales consignados eran servicios y monedas.

La carga fiscal y señorial no parece muy gravosa, pero los vecinos y el concejo debían hacer frente a otros tributos. El registro menciona las tercias reales ${ }^{6} \mathrm{y}$ un pecho forero debido por Pentecostés al tenente del castillo por el rey; además, el concejo otorgó a Ruy González de Castañeda 40 cargas de pan y 200 mrs. en San Martín por el coffecho de la guarda y una yantar en marzo. Según el Becerro de las Behetrías, el ricohombre Ruy González de Castañeda era señor del cercano lugar de Esguevillas, probablemente tras arrebatárselo a los Lara ${ }^{7}$, y pudo ejercer algún tipo de encomienda sobre Castrillo.

\footnotetext{
${ }^{4}$ Soldevila 2008, pp. 22-27, analiza más de 3.700 noticias para el condado de Empúries entre 1330 y 1335. García 2002, pp. 39-43, recoge 566 contratos de mutuum antes de 1350 para Valencia, y es sólo una de las formas de crédito analizadas.

${ }^{5}$ Martínez 1981, vol. I, p. 179. Los "yantares" consistían originalmente en una comida al señor o al rey, aunque se acabaron transformando en dinero. El "pecho" es un nombre genérico para una renta señorial. "Serna" es el nombre castellano de la corvea o día de trabajo para el señor. La "martiniega" es una renta anual pagada por San Martín de Noviembre, frecuente en el señorío del rey. La "fonsadera" un pago al rey por no acudir a la hueste. Los "servicios" y "monedas" son dos rentas reales, concedidas por las Cortes.

${ }^{6}$ Las "tercias reales" son, en principio, dos novenos de los diezmos eclesiásticos, que cobraban los reyes de Castilla desde mediados del siglo XIII.

${ }^{7}$ Estepa 2003, vol. I, p. 155.
} 
Castrillo Tejeriego pertenecía a la diócesis de Palencia (ciudad sita a unos $50 \mathrm{~km}$.), al arciprestazgo de Peñafiel, en el arcedianato de Cerrato. La Estadística Palentina (1345) señala que tenía una sola iglesia, servida por cuatro presbíteros, lo que indica un cierto potencial económico. El número de raciones asignadas a su iglesia (indicador de las rentas disponibles) era ligeramente inferior al cercano lugar de Esguevillas, poco más de la tercera parte de la villa de Dueñas y la quinta de Peñafiel ${ }^{8}$. No era, por tanto, un centro comarcal como Peñafiel o Valladolid, distantes unos $30 \mathrm{~km}$.

No hay cifras concretas sobre la población del lugar. A inicios del siglo $\mathrm{XV}$, las estimaciones fiscales apuntan, con muchas precauciones, unos 70 vecinos pecheros ${ }^{9}$. El registro de 1334 contiene una lista de propietarios de bueyes, que asciende a 25 , pero menciona muchos más vecinos (un número difícil de calcular pero que podría alcanzar 150 cabezas de familia). Se trata de un pueblo destacado en una comarca caracterizada por el pequeño tamaño de sus núcleos, pero claramente por debajo de las villas sitas sobre los ríos de la periferia del Cerrato, el Duero y el Pisuerga. La presencia del escribano Gonzalo Pérez cabe atribuirla a que era uno de los labradores de Castrillo, pues figura en la lista de propietarios de bueyes.

Otro elemento importante es la coyuntura económica. En el primer semestre de 1334 culminó una grave carestía, iniciada en Castilla con la mala cosecha de 1331 y exacerbada por la pésima de 1333, que afectó a toda la Península y en Cataluña fue conocida como el mal any primer ${ }^{10}$. El aumento del precio del cereal en los meses de soldadura de 1334 fue muy importante. En 1338 las cuentas del priorato de Santa María de Duero (a unos $20 \mathrm{~km}$. de Castrillo) valoraban la carga ${ }^{11}$ de trigo a $14 \mathrm{mrs}$. y la de cebada a 8 mrs., y las de San Zoilo de Carrión a 10 y 5 respectivamente ${ }^{12}$. Los precios recogidos en Castrillo son claramente superiores. El 30 de abril de 1334, Benito Sánchez valoró la carga de cebada en 60-64 mrs., precio que había alcanzado en el mercado de Peñafiel. No obstante, el día 12 de mayo, el cura Domingo Martín vendía una carga por 30 mrs., mientras que ese mismo mes Ruy Pérez vendía las de trigo a entre 48 y 52 mrs. En junio los precios bajaron, a

\footnotetext{
${ }^{8}$ San Martín 1951, p. 86.

${ }^{9}$ Sobre el método empleado y el recuento de fuegos de inicios del siglo XV: Reglero 1995; Ortego 2014-2015.

${ }^{10}$ Reglero 2011, p. 318; Laliena 2011, pp. 292-294; Rubio 1982; Furió 2011.

${ }^{11} \mathrm{La}$ "carga" es una unidad de medida que equivale al peso que puede transportar una bestia de carga (Covarrubias 1611, f. 138v). Las cargas aquí mencionadas se dividen en cuatro fanegas de Valladolid, o 13,5 heminas de Castrillo Tejeriego, en otros pueblos la carga tenía 14 heminas. La fanega equivalía a unos 55,5 litros, lo que supone que la carga serían unos 222 litros. Todo ello son aproximaciones, dada la gran variabilidad de la medida.

${ }^{12}$ Ferotin 1897, p. 398; Pérez 1987, p. 84.
} 
mediados de mes una carga de pan mediado (mitad trigo y mitad cebada) costaba casi 29 mrs., y, a finales del mismo, una carga de centeno se vendió por sólo 9 mrs. Más allá del alza relativa, difícil de fijar por las variaciones locales de la medida, hay que tener en cuenta que los bueyes de Castrillo se valoraron entre 25 y 70 mrs., con una media 45 . Ello supone que una carga de trigo o cebada llegó a costar en los meses de abril y mayo tanto o más que un buey.

El alza de precios se agravó por la devaluación del maravedí. El florín aniel había pasado de 20 a 22 mrs. entre enero 1332 y enero 1334. La acuñación de nuevos coronados en enero de 1334 acentuó el proceso, de modo que la dobla de oro pasó de 25 a $35 \mathrm{mrs}$., y el marco de plata de 90 a $120^{13}$. La carestía, resultado de las malas cosechas y la devaluación monetaria, empeoró por las guerras. Don Juan Manuel y don Juan Núñez de Lara se rebelaron en 1333-1334 ${ }^{14}$. El centro de actividades de don Juan Núñez fue la villa de Lerma, y las rapiñas de sus partidarios afectaron directamente a la comarca. En mayo de 1334 dos vecinos de Villavaquerín, se quejaron ante el merino del Infantazgo, por los robos y daños sufridos a manos de Juan Fernández, que vino al lugar en el rrastro de don Juan Núnez. Los vecinos de Castrillo también se vieron afectados por esta algarada. El rebaño de ovejas de la iglesia de Capelludos fue robado, junto con otros, según se denunció el 24 de abril ${ }^{15}$. A los robos se sumaron los tributos impuestos con este motivo, pues, a mediados de junio, el concejo, junto con el ricohombre Ruy González Castañeda, recaudaba entre sus vecinos quince cargas de pan, por el rrastro de don Johán Núnnez que adeuió deste logar.

\section{EL CRÉDITO Y SUS FÓRMULAS LEGALES}

El sistema crediticio castellano fue regulado por Alfonso X en la $V$ Partida a partir del Derecho Romano y Canónico, junto con algunos modelos extranjeros. Entre las fórmulas recogidas se encuentran el mutuum y el commodatum, entendidas como dos formas de préstamo (Título I), las ventas con pago aplazado (Título V), el depósito o condesijo, la compañía, los alogros y arrendamientos... El mutuum suponía la entrega de algo contable (monedas, cereal...) que pasaba a posesión del deudor, quien podía disponer de ello a su voluntad con la condición de devolverlo en el plazo estipulado.

${ }^{13}$ Ladero 1993, pp. 115-117; 2000, pp. 153-156.

${ }^{14}$ Catalán 1977, vol. II, pp. 66-67, 75-76, 81-92.

${ }^{15}$ El alcalde había llevado parte de su rebaño a Tudela, temiendo el robo, e incluso había advertido a los mayordomos de la iglesia del peligro un mes antes, el Domingo de Ramos (20 de marzo). 
Por su parte, el commodatum comportaba entregar el usufructo de un bien, del que se podía obtener un beneficio pero no enajenarlo. Igualmente se regularon las garantías del préstamo: fiadores, prendas o empeños. Siguiendo el Derecho Canónico, estaba prohibido el cobro de intereses en los préstamos entre cristianos, pero no en los que se hiciesen entre gentes de diferente credo. Las Cortes castellanas de la segunda mitad del siglo XIII y primera del XIV legislaron con frecuencia sobre esta cuestión, en especial sobre las condiciones en que los judíos podían prestar a interés a los cristianos: interés máximo, validez temporal de las cartas de deuda, formalización ante notario... También se intentó precisar el concepto de usura en las operaciones entre cristianos, prohibiendo prácticas que intentaban encubrirla ${ }^{16}$.

\subsection{El mutuum: un reconocimiento de deuda}

Casi todas las deudas que figuran en el registro (69 de 71) corresponden al mutuum: el deudor o deudores, junto con el fiador o fiadores en su caso, obligan todos sus bienes al pago al acreedor, o a qui esta carta mostrare, de una cantidad de dinero o cereal que reconocen haber recibido prestada, por nos ffazer amor; se establece la fecha y lugar de pago, y la pena por cada día de retraso. Las ventas con pago aplazado se formulan también bajo la fórmula del mutuum, pudiendo hacer constar que derivan de la adquisición de cierta cantidad de cereal o carne (16 casos). A veces, el mutuum está ligado a un contrato de arrendamiento de tierras (3), ya sea en la misma nota, ya en dos consecutivas. Hubo situaciones intermedias: préstamos de cereal que se pueden devolver en cereal o dinero (6), lo que supone una venta; préstamos en dinero que pueden devolverse en dinero o en cereal después de la cosecha (9), lo que encubre la venta anticipada de la cosecha; coincidencia de la cantidad de dinero adeudada con lo pagado por una medida de cereal o alimentos en las mismas fechas (7); una deuda que el comprador de una heredad reconoce al vendedor en el registro siguiente a la compraventa (1). Todo ello supone que, de los 69 contratos de mutua registrados, 39 están ligados a una compraventa y tres a un arrendamiento. Por tanto, no más de 27 de los mutua podrían ser préstamos de dinero (21) o cereal (8) en un sentido estricto, si bien, tras varios de ellos puede haber una compraventa, una renta o tributo no pagados.

Dentro de esta fórmula general pueden distinguirse dos modalidades específicas: la venta a crédito y el préstamo ligado a un arrendamiento. La venta con pago diferido está bien documentada en la Corona de Aragón,

${ }^{16}$ Carvajal 2013, pp. 50-109; Castán 1983, pp. 67-76. 
siendo muy habitual en la adquisición de paños ${ }^{17}$. En el registro de Castrillo se emplea para la compra de alimentos, tanto cereales como carne de cerdo, y, en una ocasión, para una pequeña cantidad de pan y paños conjuntamente. Presenta dos modalidades básicas, una en que se fija el precio en moneda desde el momento de la venta, y otra en que aquel depende del que se alcance en el mes de mayo en los mercados de la comarca. Ejemplo de lo primero son las cinco ventas de tocinos $^{18}$ en febrero $(1334,1335)$ por entre 9 y 51 mrs., a pagar en cuatro casos en San Antolín (2 de septiembre) y en el otro en Santa Marina (18 de julio $)^{19}$ :

Cómmo yo, Domingo Iohán ffijo de Domingo Iohán e yo Domingo Pérez ffijo de Yuán Pérez, vezinos moradores que somos en Castriell Traseriego, obligamos a nos e a todos nuestros bienes, así muebles commo rraýzes, por dar, pagar a uos, Johán Ferrnández ffijo de don Tomé de Villamediana, morador en la casa de San Rromán, o a qui esta carta mostrare, debda conosçida treynta maravedís desta moneda vsual, a diez dineros el maravedís, los quales maravedís uos auemos a dar por vn toçino que nos uendiestes por estos dichos maravedís, de que somos bien pagados. Et ponemos conuusco de uos dar estos dichos maravedís al día de Sant Antolín de setienbre primero que vien, so pena de dos maravedís por cada día adelante (f. $24 \mathrm{v}$ ).

Del mismo modo, nueve ventas de trigo o cebada (entre una hemina y una carga) en mayo de 1334 se pagarían el día de Santa María de Agosto (15 de agosto); los deudores especificaban que la cantidad adeudada correspondía a vna ffanega de trigo que me diestes, de que so bien pagado ${ }^{20}$.

Una modalidad diferente de venta a crédito es la realizada por Benito Sánchez, el mayor prestamista del lugar, y en una ocasión por Ruy Pérez. Once registros, de los que cuatro son reclamaciones o cobros de la deuda, se refieren a préstamos de cereal (trigo, cebada o centeno). La fecha de pago se fijó entre el 1 de mayo y el 1 de junio, y el precio en los mrs. que ualiere la dicha çeuada en el primero mercado de mayo este primero que vien que ffizieren en esta comarca, o fórmulas similares. La entrega del cereal se realizaba entre

\footnotetext{
${ }^{17}$ García 2002, pp. 71-83.

${ }^{18} \mathrm{Ha}$ de entenderse como el cerdo después de la matanza, sin las vísceras ni el lomo (Covarrubias 1611 , f. 189r).

${ }^{19}$ Es probable que otra deuda, de la que no se precisa el motivo, encubra este tipo de ventas, como se aclara en el encabezamiento del registro que sigue a las cuatro ventas de tocinos de febrero de 1335, si bien el plazo se establece en San Miguel.

${ }^{20}$ Como en el caso de los tocinos, se intuye que otras cuatro deudas en favor de Ruy Pérez, en esos mismos días y por cantidades similares de dinero, corresponden también a ventas a crédito de trigo. Lo mismo sucede con otras dos en junio en favor de Ruy Pérez y de su padre, el escribano Gonzalo Pérez.
} 
enero y marzo, pero el precio era el de mayo. En ocasiones se precisó el día en que se fijaría el precio, e incluso en qué mercado: el primero que se celebre en la comarca, el primer jueves del mes en Peñafiel. En estos casos, el beneficio deriva del momento en que se fija el precio, coincidiendo con las semanas en que alcanzaba su máximo anual.

Un caso especial de venta a crédito se registra a inicios de septiembre de 1334, cuando el clérigo Benito Pérez y dos laicos se comprometen a pagar $44 \mathrm{mrs}$. por la uva de un majuelo de la cofradía de Santa María de Capelludos, lo que supone que estaban comprando la uva que debía vendimiarse. El pago se posponía hasta el inicio de la Cuaresma, el día de Entroido de 1335 (27 de febrero), es decir, cuando ya podían vender el vino.

Por otra parte, tres deudas están ligadas a sendos arrendamientos de tierras. En septiembre y noviembre de 1334, Fernando Martínez y Nicolás Martínez, ambos hijos de Martín Pérez, que no residían en Castrillo Tejeriego, arrendaron por tres o cuatro años las tierras que habían heredado de su padre. En el primer caso, el arrendatario reconoció, a continuación, una deuda con el arrendador de dos cargas de trigo, que se comprometió a pagar el día de San Antolín de 1335 (ese año no tenía que pagar renta). En el segundo caso, en un mismo documento, los arrendatarios reconocieron deber al arrendador 80 mrs.; devolverían la cuarta parte en San Antolín de 1335 (año en que tampoco pagarían renta) y el resto al final del arrendamiento, por San Miguel. De forma similar, cuando Pedro Rodríguez, clérigo de Quintanilla, arrendó su herencia en Castrillo a su hermano Ruy Pérez, le prestó 40 mrs., a devolver en septiembre del último año de la renta. En ningún caso se precisa si la deuda procede de un arrendamiento o préstamo anterior, o bien, si es un mecanismo para facilitar el cultivo de la heredad entregada. Así, en dos de los tres casos el préstamo debía devolverse al final del contrato o funcionaba como primer plazo del arrendamiento.

\subsection{Commodatum: el usufructo de la heredad como interés}

La segunda fórmula de préstamo es denominada commodatum en las Partidas. Su importancia es mucho menor, pues solo se conservan dos registros con esta fórmula, aunque hay otras noticias. En general, se entrega una tierra o solar a cambio de la cantidad de dinero concedida; el acreedor labra o hace labrar la tierra y se queda con la cosecha hasta que el deudor devuelve el préstamo. Los dos registros en que se utiliza esta fórmula corresponden a la misma acreedora, María Pérez, hija de don Rodrigo, freira en la iglesia de Santa María de Capelludos. En octubre de 1334 un vecino de Castrillo le empeñó varias tierras por 60 mrs.; las recuperaría cuando devolviese esa can- 
tidad, si bien, si las tierras estuviesen entonces aradas, barbechadas o sembradas, la acreedora tendría derecho a recoger la cosecha. Quien tomó las tierras para cultivarlas fue don Romero, un sobrino del deudor. Con ello, las tierras quedaban dentro de la familia, sujetas al pago de la renta correspondiente a la acreedora.

Estas tierras sobredichas enpenno a la dicha María Pérez, <§ por setenta maravedís desta moneda vsual>, e a uos, el dicho don Rromero en su nonbre, en tal manera e so tal condiçión, que lo labredes uos o otre en nonbre de la dicha María Pérez commo labraría <e esquilmaría> la otra heredat suya ffasta quel dé estos dichos setenta maravedís. Et quando uos las yo o otre por mí quisiere quitar estas dichas tierras, si la dicha María Pérez o otre por ella, en su nonbre, las touiere aradas o barbechadas o senbradas, que las esquilme ese anno primero siguiente e que me non dé a mí ninguna cosa de lo que ende viniere del esquilme (f. 16v).

Un mes después, María prestaba 100 mrs. a Juan Domínguez, quien empeñaba la parte que había correspondido a sus hijos en el solar de su abuelo don Aparicio, con unas casas y corral. La acreedora se podría servir del solar, con su casa, durante dos años, y, si en ese tiempo no se le había pagado la deuda, podría venderlo. El deudor estaba obligado a retejar la casa y reparar las paredes que cayeren. Juan Domínguez y don Romero eran yernos de don Aparicio.

La deuda podía enajenarse a un tercero, que recibía la tierra o prenda con las mismas condiciones. Así, cuando un matrimonio de Sinova vendió a Benito Sánchez una tierra en ese lugar, declararon que la mitad de dicha tierra era de Pero Fijo, y ellos la tenían en pennos por çinco maravedís, de forma que si el propietario pagaba esa cantidad, Benito debía devolvérsela; como en el caso anterior, si la tenía labrada ese año, tendría derecho a recoger la cosecha. Una variante de este tipo de crédito se verifica cuando los recaudadores de un tributo concejil venden la propiedad de un vecino para cobrar lo que debía pagar. Se prevé la posibilidad de recuperar la heredad mediante el abono del precio de venta. De nuevo, el comprador tendría derecho a cosechar la tierra si ese año la tenía arada. Por tanto, el comprador no adquiría la plena propiedad, al menos temporalmente.

\section{BENEFICIOS Y GARANTÍAS DEL PRÉSTAMO}

Los mutua recogidos en el registro se realizan entre cristianos, entre los que estaba prohibido el cobro de intereses. El préstamo se presenta como una ayuda, de ahí el empleo de la expresión que me/nos prestastes por me/ 
nos ffazer amor en 31 registros de reconocimiento de deuda (43\%). Se emplea en la mayoría de los casos de compra de la cosecha por anticipado (7/8) y de préstamos en cereal que se devuelven en cereal (6/7), pero rara vez en las ventas a crédito $(2 / 28)$. En los préstamos en dinero a devolver en dinero aparece en algo más de las mitad de las ocasiones (17/30). Benito Sánchez, el principal acreedor, recurre a esta fórmula en casi la mitad de las ocasiones tanto de compras adelantadas de la cosecha como de préstamos a devolver en dinero.

En las ventas a crédito, la ganancia del acreedor se conseguía al fijar el precio de venta cuando el cereal alcanzaba su máximo. El aplazamiento del pago permitía al comprador adquirir el producto, ampliaba el mercado de compradores potenciales y, consecuentemente, hacía que los precios subiesen. El empleo de la fórmula por me fazer amor no demuestra que no se cobrase un interés por el préstamo y, si no buscaba meramente encubrirlo, podría expresar una forma de establecer relaciones de favor-obligación entre acreedor y deudor: algunos préstamos se realizan entre familiares, vecinos, incluso entre el señor del lugar y el concejo.

Las Partidas se refieren a dos tipos de garantía de la deuda: el fiador y la prenda. Dado que los deudores obligaban todos sus bienes al pago, no se suele especificar ninguna prenda. Tan sólo en una ocasión se concretó la obligación en un solar. La razón puede encontrarse en el interés del acreedor por adquirirlo, pues dicho solar lindaba con el suyo. De hecho, la cantidad prestada es relativamente reducida (20 mrs.). La ausencia de registros fiscales impide conocer el valor de las propiedades de los deudores. No obstante, de los 43 que eran vecinos de Castrillo, al menos 20, tal vez 25, se documentan como propietarios de tierras o de bueyes. En otro caso, la mujer del deudor es quien obliga sus bienes al pago de una deuda. Por tanto, al menos la mitad de los deudores poseían bienes inmuebles con que afrontar el pago.

El recurso a los fiadores se documenta tan sólo en 18 contratos, la cuarta parte del total. Suele tratarse de un fiador, pero en tres ocasiones son dos y en una, tres. Se conoce un total de 21 fiadores, pues dos se repiten. En seis casos se trata de parientes cercanos de los deudores: hermano (2), padre (1), suegro (2) o yerno (1); y en otros cinco, de vecinos del mismo lugar. Ello supone que en la otra mitad de los casos no hay relación de parentesco conocido ni vecindad. Otro elemento a destacar es que diez de los fiadores figuran como deudores en otros documentos, lo que implica que eran considerados solventes.

La mitad de las deudas con fiadores tienen más de un deudor, hasta cinco. En total 30 deudas fueron contraídas por más de un deudor (42\%). Con ello, el mancomunamiento de deudas se convertía en una garantía, más frecuente que el recurso a los fiadores. Como en el caso de los fiadores, en casi la tercera parte de los casos se trata de parientes cercanos (padres e hijos, ma- 
trimonios, hermanos o cuñados), pero lo más habitual es que sólo se explicite una relación de vecindad, si es que existe ${ }^{21}$.

Otra de las garantías implícita en algún contrato es la cosecha de las tierras cultivadas por los deudores, ya fuesen de su propiedad o arrendadas ${ }^{22}$. Desde un punto de vista formal no hubo compraventas de la cosecha por anticipado u obligación de una tierra específica al pago, sino que el acreedor ofrecía al deudor una doble posibilidad: devolver la deuda en dinero en cierta fecha o entregar la cantidad equivalente de cereal. En este último caso, el cereal debía ser transportado a Valladolid, el principal mercado de la comarca, a costa del deudor, siendo valorado por el precio que allí se pagase la fecha fijada, entre Santa María de Agosto y San Antolín de Septiembre, precisamente cuando los precios del cereal alcanzaban su mínimo por la elevada oferta. Dado que la cantidad prestada era superior a la media, entre los 100 y 200 mrs. en cinco casos, la operación puede interpretarse como una garantía adicional para el acreedor.

Existe, pues, una clara relación entre las fechas de cobro y el calendario agropecuario. Por ello, cuando el pago de la deuda consiste en la entrega de quince ovejas, preñadas y paridas, con sus hijos, se fija como fecha de devolución la Pascua de Resurrección (el préstamo es en diciembre), porque las ovejas suelen parir en los meses de invierno.

\section{El OBJETO DEL PRÉSTAMO Y LOS PLAZOS DE DEVOLUCIÓN}

\subsection{La dimensión temporal del crédito}

El número de registros que contienen un reconocimiento de deuda se eleva a 71. Todos los meses hay al menos un registro, siendo lo más frecuente que fuesen dos o tres. Por encima de esta cifra se encuentran 4 de los 17 meses en los que hay datos: febrero de 1334 (8) y 1335 (7), mayo (22) y junio (9) de 1334. Desgraciadamente el registro termina a inicios de mayo de 1335 , por lo que no es posible comparar los dos primeros semestres de ambos años y conocer el verdadero impacto de la carestía de 1334. En cualquier caso, hay una clara concentración de créditos en el primer semestre del año 1334, cuando se realizaron tres cuartas partes de los del año.

El elevado número de créditos en los meses de mayo y junio responde a su condición de meses de soldadura, cuando muchos campesinos ya

\footnotetext{
${ }^{21}$ Algo ya señalado para el caso barcelonés: Fernández 1998, pp. 178-182.

${ }^{22}$ Soldevila 2008, pp. 198-207.
} 
habían agotado sus reservas de cereal y debían conseguir el necesario para subsistir hasta la nueva cosecha. De todos modos, en el caso estudiado, ello se ve acentuado por la política comercial de los principales prestamistas. Estos prestaban en cereal durante los primeros meses del año, estableciendo el precio en función del que se alcanzase en los mercados comarcales, en concreto en Peñafiel, durante el mes de mayo. Esta cláusula puede estar incluida en el contrato, o bien, realizarse un primer crédito en cereal a devolver en mayo, y un segundo crédito en este mes en dinero, por el valor del cereal. Por ello, no es seguro que las ventas a crédito registradas dicho mes fuesen realizadas entonces y no antes.

Se conoce el plazo otorgado en 69 contratos. Hay un claro predominio de las deudas a corto plazo, de forma que sólo en cuatro casos se supera el año. El plazo más habitual, dos terceras partes del total, se sitúa entre dos y cuatro meses. Los préstamos realizados entre septiembre y febrero tienden a ser más largos que los de primavera, pues las fechas de devolución coinciden en agosto-septiembre, tras la cosecha. Hay también un pequeño pero significativo grupo de préstamos a muy corto plazo, de menos de un mes, que parecen responder al aplazamiento de un pago anterior (o bien un crédito puente con otro acreedor) o a una necesidad puntual no concretada. Todo ello es común con otros espacios hispanos mejor documentados ${ }^{23}$.

Tabla 1: Plazo de las deudas

\begin{tabular}{|c|c|}
\hline PLAZO & NÚMERO DE DEUDAS \\
\hline menos de 1 mes & 6 \\
\hline 1-2 meses & 1 \\
\hline $2-3$ meses & 20 \\
\hline $3-4$ meses & 24 \\
\hline $4-5$ meses & 2 \\
\hline 5-6 meses & 4 \\
\hline 6-7 meses & 4 \\
\hline 7 a 12 meses & 4 \\
\hline más de 1 año & 4 \\
\hline
\end{tabular}

${ }^{23}$ García 2002, pp. 96-100, 129-131. Soldevila 2008, pp. 84-88, 161-164. 


\subsection{Préstamos en cereal y préstamos en dinero}

La mayor parte de los préstamos se contabilizaron exclusivamente en dinero (lo que no implica necesariamente que el acreedor entregase moneda al deudor). No obstante, en 13 casos se entregó una cantidad de cereal y en otros 3 dinero y cereal conjuntamente. En 15 casos la deuda procede de una venta de cereal o carne, pero desde el inicio se contabiliza en dinero. La diferencia entre el préstamo de cereal y la venta a crédito se difumina cuando se exige devolver el cereal en el mes de mayo (antes de que el deudor pudiese cosechar) o bien pagar el dinero que tal cantidad de cereal valiere en el mercado (ocho de los 13 casos) ${ }^{24}$. Por tanto, solo cinco préstamos en cereal pueden ser devueltos en cereal después de la cosecha (entre el 15 de agosto y el 2 de septiembre), lo que supone menos de la décima parte del total ${ }^{25}$. En apariencia las condiciones son mejores en estos préstamos, pues no se establece ningún interés, aunque sí las habituales multas por retraso.

El plazo para la devolución de los préstamos en cereal, como se ha señalado, se reparte en dos momentos: entre el 16 de abril y el 1 de junio (siete casos) y entre el 15 de agosto y el 2 de septiembre (cinco casos). En los contratos mixtos, en cereal y dinero, cuando el valor del cereal prestado es muy superior al del dinero, se fija el mes de mayo (un caso), y cuando el valor del dinero es superior al del cereal, el 15 de agosto (dos casos).

En tres de cada cuatro casos la deuda se valora únicamente en dinero, lo que no obsta para que se trate de una compraventa con pago aplazado, ya se indique así abiertamente o se deduzca de la cantidad. Lo habitual es que el plazo no exceda de un año, aunque hay excepciones. El plazo más largo lo obtuvo un clérigo, beneficiado en la iglesia de Santa María de Valbuena, quien tomó prestados 400 mrs., la cantidad más elevada con excepción de las deudas del concejo. Se comprometió a devolverlos en ocho años, a razón de 50 mrs. anuales, pagaderos cada Santa María de Agosto. Como garantía entregó al acreedor las rentas que le correspondían en dicha iglesia. Dado que tales

\footnotetext{
${ }^{24}$ En una ocasión, se presta en cereal y se fija el plazo de devolución para Pascua de Resurrección, lo que parece ocultar que en dicho momento el préstamo de cereal se transformaría en su valor en dinero, es decir, que se trata del primer paso de una venta a crédito con fijación diferida del precio.

${ }^{25}$ Uno de ellos está ligado a un arrendamiento. En otro, el deudor, Ruy Sánchez hijo de Sancho Ruiz de Gaona, vecino de Villavaquerín, puede ser un pariente cercano del tenente del castillo, Juan Ruiz de Gaona. En el Becerro de las Behetrías, entre los señores de Villavaquerín aparecen los hijos de Juan Ruiz de Gaona (Martínez 1981, vol. I, p. 177). En un tercero, el acreedor es el alcaide del castillo, que presta a tres vecinos del lugar, tal vez aplazando el pago de un tributo: el préstamo se realiza el 19 de junio, después de que el 1 de junio, el alcaide hubiese reclamado el pago de un tributo por la tenencia del castillo.
} 
rentas consistirían fundamentalmente en parte de los diezmos del lugar, el acreedor estaba comprando por anticipado cereal, vino y otros productos. En las otras dos ocasiones se trata de arrendamientos a tres años, en los cuales la deuda en dinero se paga al final del contrato, en la segunda quincena de septiembre, tras la última cosecha. Finalmente, en los commodata no suele fijarse plazo de devolución de la deuda, aunque en uno la acreedora podría vender la heredad empeñada al cabo de dos años.

El pago de 49 de las deudas en dinero se fijó en menos de un año y en un solo plazo, marcado por una festividad. En 32 ocasiones esta festividad fue Santa María de Agosto (15 de agosto), en siete San Antolín (2 de septiembre) y en dos en San Miguel (29 de septiembre). Santa Marina (17 de julio) o el 1 de agosto solo figuran una vez y para cantidades pequeñas. Ello supone que en el $88 \%$ de los contratos, la deuda debía devolverse justo después de la cosecha. En este sentido, la fecha de devolución es más importante que la fecha de realización del préstamo. Otros tres casos parecen relacionados con otros ciclos agropecuarios. Así, quienes compraron la uva del majuelo de la cofradía de Capelludos, se comprometieron a pagar a finales de febrero, lo que está relacionado con la producción de vino; un pago en ovejas de un préstamo en dinero se efectúa a mediados de abril, tras la paridera; un clérigo se compromete a pagar a su hermano parte de una venta mediada la feria de Cuaresma en Valladolid, lo que sugiere que pensaba vender allí algún producto, tal vez vino. Un préstamo en febrero por sólo dos semanas sugiere que el deudor, un clérigo, pensaba conseguir el dinero rápidamente. Más difícil resulta saber si los realizados en diciembre y enero para pagar en junio (Pentecostés o San Juan), pudieron ser satisfechos a tiempo o, más bien, los deudores tuvieron que recurrir a un nuevo préstamo.

El pago en dos fechas en un año es excepcional (tres casos). En una deuda del concejo de Castrillo Tejeriego a su señor (diciembre de 1334), se establece el pago de la mitad en Carnestolendas (1 de marzo) y de la otra en Santa María de Agosto. La elevada suma adeudada, 800 mrs., explica que la cantidad se dividiese. En los otros dos casos se trata de préstamos entre particulares. En el primero, hay un problema de liquidez del deudor: Pedro Fernández Saquero recibió un préstamo a inicios de junio, que no pudo devolver; a finales de agosto se comprometió a pagar su deuda en dos plazos, San Miguel (29 de septiembre) y San Martín (11 de noviembre) que tampoco pudo solventar a tiempo. En el segundo, las dos fechas de pago son muy próximas, 4 y 24 de junio (Cinquesma y San Juan), para un préstamo realizado en enero, por lo que hay que pensar que el deudor consideraba que obtendría ingresos suficientes a lo largo de dicho mes. 
Tabla 2: Fecha de cobro de préstamos en cereal o dinero

\begin{tabular}{|l|c|}
\hline \multicolumn{1}{|c|}{ PERIODO } & CASOS \\
\hline Cuaresma a Pasqua (fines de febrero-mediados de abril) & 5 \\
\hline 1 mayo a 4 junio & 8 \\
\hline 24 junio a 1 agosto & 3 \\
\hline Santa María de agosto (15-VIII) & 35 \\
\hline San Antolín de septiembre (2-IX) & 10 \\
\hline Navidad (25-XII) & 1 \\
\hline dos fechas & 4 \\
\hline
\end{tabular}

\section{LOS ACREEDORES}

El número de acreedores asciende a 19, de los que ocho (42\%) no eran vecinos de Castrillo. Tres proceden de lugares dentro de un radio de $12 \mathrm{~km}$. (dos de Quintanilla de Yuso y uno de la casa de San Román), tres moraban en Valladolid (dos hijos de un vecino de Castrillo y el obispo de Osma, señor del lugar) y uno en Peñafiel (un judío).

Tabla 3: Los acreedores del registro de Castrillo Tejeriego

\begin{tabular}{|l|c|c|c|c|}
\hline NOMBRE & $\begin{array}{l}\text { NÚMERO DE } \\
\text { PRÉSTAMOS }\end{array}$ & MRS. & $\begin{array}{l}\text { CARGAS } \\
\text { DE CEREAL }\end{array}$ & $\begin{array}{l}\text { ADQUISICIÓN } \\
\text { DE HEREDADES } \\
\text { (MRS.) }\end{array}$ \\
\hline $\begin{array}{l}\text { Acreedores vecinos de } \\
\text { Castrillo Tejeriego }\end{array}$ & 31 & 1695,5 & 23 & 523 (y 4 ovejas) \\
\hline $\begin{array}{l}\text { Benito Sánchez hijo de Martín } \\
\text { Pérez }\end{array}$ & 10 & 325 & 1,5 & 350 (y 11 ovejas) \\
\hline Domingo Martínez, cura & 16 & 223 & 3 & 110 \\
\hline $\begin{array}{l}\text { Ruy Pérez y } \\
\text { Gonzalo Pérez escribano, su } \\
\text { padre }\end{array}$ & 3 & 200 & & 16 \\
\hline $\begin{array}{l}\text { María Pérez hija de don } \\
\text { Rodrigo }\end{array}$ & 2 & 76 & & \\
\hline $\begin{array}{l}\text { Don Rodrigo hijo de don } \\
\text { Rodrigo }\end{array}$ & 1 & 44 & & \\
\hline Cofradía de Capelludos & & & & \\
\hline
\end{tabular}




\begin{tabular}{|l|c|c|c|c|}
\hline Juan González clérigo & 1 & 25,5 & 0,3 & 11 \\
\hline Martín Pérez, portero del rey & 2 & 23 & & 100 \\
\hline Ruy Martínez alcaide & 2 & 12 & 2,5 & \\
\hline $\begin{array}{l}\text { Pedro Fernández yerno de } \\
\text { Pedro Martín }\end{array}$ & 1 & & 3 & \\
\hline & 1 & 800 & & \\
\hline $\begin{array}{l}\text { Acreedores no moradores en } \\
\text { Castrillo Tejeriego }\end{array}$ & 3 & 101 & & \\
\hline Obispo de Osma & 1 & 80 & & \\
\hline $\begin{array}{l}\text { Juan Fernández hijo de don } \\
\text { Tomé de Villamediana, } \\
\text { morador en la casa de San } \\
\text { Román }\end{array}$ & 1 & 40 & 3675 ovejas) \\
\hline $\begin{array}{l}\text { Nicolás Martínez hijo de } \\
\text { Martín Pérez, vecino de } \\
\text { Valladolid }\end{array}$ & 1 & 30,5 & & \\
\hline $\begin{array}{l}\text { Pedro Rodríguez, clérigo de } \\
\text { Quintanilla }\end{array}$ & 1 & & & \\
\hline $\begin{array}{l}\text { Sancho Rodríguez de } \\
\text { Quintanilla }\end{array}$ & 1 & & & \\
\hline Ruy González de Fuente Cirio & 1 & & & \\
\hline $\begin{array}{l}\text { Fernando Martínez hijo de } \\
\text { Martín Pérez }\end{array}$ & $\begin{array}{l}\text { Don Creciente, judío de } \\
\text { Peñafiel }\end{array}$ & 19,3 & \\
\hline \begin{tabular}{l} 
TOTAL \\
\hline
\end{tabular} & 1 & & & \\
\hline
\end{tabular}

El acreedor que aparece con más frecuencia es Benito Sánchez, que presta tanto cereal (11 operaciones) como dinero $(20)^{26}$. Buena parte de sus actividades están ligadas al comercio de cereal, pues casi todos los préstamos contabilizados en cereal se han de pagar en dinero al precio alcanzado en el mes de mayo, es decir, son ventas a crédito. Igualmente, la mitad de los préstamos en dinero (que suponen más de cuatro quintas partes de la cantidad total) se devuelven en especie: ya sean compras adelantadas de la cosecha de cereal o de ovejas, ya rentas eclesiásticas. Benito es, pues, un mercader que

\footnotetext{
${ }^{26}$ Un registro se refiere a Benito Pérez hijo de Martín Pérez de Castrillo, probablemente un error por Benito Sánchez.
} 
presta dinero en el marco de su actividad comercial. Era vecino de Castrillo Tejeriego, pero tenía fuertes lazos con Valladolid (en junio de 1334 el concejo tuvo que enviar apoderados a Valladolid para tratar con él sobre un préstamo, y su hermano Nicolás Martínez moraba en Valladolid).

Benito Sánchez no figura entre los propietarios de bueyes en Castrillo, aunque sí de tierras. Además, a lo largo de estos dos años, compró 15 tierras en Sinova, una aldea lindante con Castrillo, invirtiendo 523 mrs. y cuatro ovejas, lo que equivale a casi un tercio del dinero prestado. En una ocasión se precisa que pagó 60 mrs. por 4 obradas, lo que supondría que pudo adquirir una treintena de obradas ${ }^{27}$, si hubiese pagado un precio similar por el resto. Hay que destacar que las compras se realizaron, en ambos años, entre fines de enero y mayo, pero no entre junio y diciembre de 1334, lo que muestra que Benito aprovechaba los meses en que las necesidades económicas del campesinado eran mayores.

Las ventas a crédito, préstamos en dinero y compras realizadas por Benito Sánchez están relacionadas a veces. Así, en febrero de 1334, Gómez Fernández, Domingo Fernández y doña Yllana recibieron dos cargas de centeno y $20 \mathrm{mrs}$., a pagar el primer jueves de mayo según lo que valiese el pan en el mercado de Peñafiel de ese día. A finales de mayo, Gómez vendía a Benito una tierra en Sinova por 30 mrs.; ese mismo día, junto con el referido Domingo, recibían un préstamo de $120 \mathrm{mrs}$. (el precio de dos cargas de cebada), a pagar por San Antolín en dinero o cereal, lo que puede interpretarse como una forma de cancelar el anterior préstamo. En marzo de 1335 Gómez volvió a vender a Benito dos tierras, por valor de $60 \mathrm{mrs} .{ }^{28}$.

El segundo acreedor por volumen de capital prestado fue Domingo Martín, clérigo y cura de Castrillo Tejeriego. Realizó diez préstamos, nueve en dinero, entre mayo y mediados de junio de 1344, a devolver en Santa María de Agosto; en un caso se precisa que lo adeudado correspondían a una carga de cebada, y que el deudor pagaría en dinero o cebada según quisiese la iglesia de Santa María. Esto último hace sospechar que Domingo Martín pudo actuar en nombre de su iglesia, vendiendo las reservas de cereal de la misma a seis vecinos de Castrillo y a dos de pueblos próximos. Domingo Martín también compró siete tierras a lo largo del año y medio del registro, con una inversión similar al dinero prestado, pero ninguno de los vendedores figura entre sus deudores.

\footnotetext{
${ }^{27}$ Una obrada es la cantidad de tierra que pueda labrar una yunta de bueyes en un día, en torno a media hectárea.

${ }^{28}$ Juan Martín, clérigo, compró a crédito a Benito Sánchez una carga de cebada en enero de 1334, y le vendió una tierra por 30 mrs. en marzo de 1335. Martín Pérez, vecino de Villavaquerín, tras vender a Benito cuatro tierras entre marzo de 1334 y enero de 1335, le compró a crédito una carga de centeno en febrero de este último año.
} 
El tercer lugar entre los acreedores lo ocupa Ruy Pérez, hijo del escribano Gonzalo Pérez. Su actividad es difícil de separar de la de su padre, pues Ruy le cede varias de las deudas, en compensación de las que tenía con él. Aunque el número de operaciones realizadas sea la mitad que el de Benito Sánchez, su valor no alcanza la sexta parte de las de aquel, pues las cantidades prestadas son más reducidas, entre 4 y $26 \mathrm{mrs}$. Casi todos sus préstamos se conceden entre mediados de mayo y mediados de junio de 1334, a devolver por Santa María de Agosto. En nueve casos se especifica que se trata de una venta a crédito de distintas cantidades de trigo (una hemina, una fanega, media carga), a $52 \mathrm{mrs}$. la carga, inferior al que cobraba Benito Sánchez por esas mismas fechas (60 mrs. la carga de cebada). Es probable que algunos de los otros seis préstamos en dinero realizados en ese mes correspondan a ventas a crédito, pues las cantidades equivalen al precio de una o dos fanegas. Llama la atención que, en tres casos, cuando la cantidad prestada es ligeramente superior o inferior al precio de dicho cereal, se incluya la cláusula por nos fazer amor, ausente en las ventas a crédito. El último préstamo, abril de 1335, se realizó en cereal, fijándose su devolución para mediados de mayo, en espera de que el trigo y centeno alcanzasen su precio máximo. El deudor ya había contraído otra deuda el año precedente, siendo el único que recibe dos préstamos, aunque puedan aparecer un padre y un hijo en contratos diferentes. Hay que destacar que dos de los deudores terminaron vendiendo una tierra a Ruy Pérez ${ }^{29}$.

El resto de los acreedores tienen estrategias económicas diferentes. María Pérez, hija de don Rodrigo y freira de la iglesia de Capelludos, presta dinero en tres ocasiones, por un total de $190 \mathrm{mrs}$; ; en dos de ellas utiliza la fórmula del commodatum, en una actitud claramente rentista. Por el contrario, su hermano don Rodrigo vende a crédito tres tocinos por $76 \mathrm{mrs}$. en dos operaciones; el mismo día, Juan Fernández realizaba otras tres ventas a crédito de tocinos por un total de $101 \mathrm{mrs}$., sin que se sepa si existe una relación comercial entre ambos acreedores. $\mathrm{Al}$ menos tres préstamos se verifican entre familiares, en dos casos en el marco del reparto de la herencia paterna ${ }^{30}$. Tres préstamos en dinero o cereal los hacen sendos arrendadores de tierras a sus arrendatarios. En cuanto a los dos realizados por Ruy Martínez, alcaide de

\footnotetext{
${ }^{29}$ Domingo Martín, hijo de don Bernabé, en mayo de 1334 se endeudó en 13 mrs. por una fanega de trigo, y en junio vendió una tierra a Ruy Pérez por 20 mrs. Doña Mayor, viuda de don Antolino, a inicios de junio se endeudó en $12 \mathrm{mrs}$. y el 16 de agosto, al día siguiente de que expirase el plazo para pagar, le vendió una tierra por $15 \mathrm{mrs}$. Doña Mayor ya había vendido dos viñas a Gonzalo Pérez a finales de mayo, por 15 mrs., el valor de una fanega de trigo.

${ }^{30}$ Juan González, clérigo, prestó a su tío Yuanes Domingo (25,5 mrs. y 3 heminas de trigo). Sancho Rodríguez a su hermano Juan Rodríguez, clérigo (30,5 mrs.) y Pedro Rodríguez, clérigo de Quintanilla, a su hermano Ruy Pérez (40 mrs.), los cuatro eran hijos de Domingo Rodríguez.
} 
Castrillo Tejeriego, uno en cereal y otro en dinero, en junio y julio de 1334, a devolver en Santa María de Agosto, podrían corresponder al aplazamiento del tributo que los vecinos debían al alcaide por la tenencia del castillo. De forma similar, los 800 mrs. debidos por el concejo a su señor pueden proceder tanto de un préstamo en efectivo como de una renta aplazada.

Si se examina el total de dinero prestado, al margen del cereal, las diferencias entre los acreedores son notables. Benito Sánchez concentra el 46\%, el doble que el obispo de Osma (22\%). Muy por detrás se encuentran el cura Domingo Martín (9\%), Ruy Pérez y su padre Gonzalo Pérez (6\%) o María Pérez (5\%); el resto apenas superan en conjunto el $10 \%$ del total. En cuanto al cereal, de nuevo Benito Sánchez ocupa el primer lugar (53\%), mientras que ahora Ruy Pérez (7\%) dobla a Domingo Martín (3,5\%); los demás suman aquí más de la tercera parte.

Hay que destacar los vínculos de parentesco que unen a varios de los acreedores. Nicolás Martínez y Fernando Martínez eran hermanos de Benito Sánchez. María Pérez, freira de Capelludos, y don Rodrigo eran hijos de don Rodrigo; Pedro Rodríguez, clérigo de Quintanilla, y Sancho Rodríguez eran hijos de Domingo Rodríguez, y prestaron a sus hermanos en el contexto de la redistribución de la herencia paterna. Finalmente el escribano Gonzalo Pérez, además de dos pequeños préstamos, recibe varios de los realizados por su hijo como pago, por lo que éste le debía. Ello supone que la mitad de los acreedores se integran en cuatro grupos de parientes.

\section{LOS DEUDORES}

El número de deudores se acerca al centenar, superando al de deudas. Ello se debe a que el $40 \%$ de las deudas fueron contraídas por, o reclamadas a, más de un individuo. Las situaciones son muy variadas: desde el concejo y grupos familiares (siete matrimonios, cinco padres o abuelos con sus hijos o nietos, tres grupos de hermanos o cuñados), hasta conjuntos de entre dos y cinco personas, entre las que puede haber algún pariente (21). Este endeudamiento en grupo es más frecuente que la presentación de fiadores como garantía de pago. Por otra parte, no hay una relación directa entre el tamaño del grupo y la cantidad prestada.

Casi la mitad de los deudores no eran vecinos de Castrillo Tejeriego, sino que se repartían por doce lugares de la comarca, nueve de ellos situados en un radio de diez kilómetros en torno a Castrillo y otros tres entre 15 y $22 \mathrm{~km}$. Dos tercios de estos préstamos corresponden a Benito Sánchez, pero otros ocho acreedores también prestaron a vecinos de la comarca. Hay que destacar que las deudas mancomunadas son más frecuentes entre los deudores 
de fuera de Castrillo Tejeriego, pues el $46 \%$ se realizaron a grupos (entre dos y cinco individuos), frente al $33 \%$ en el caso de los vecinos del lugar.

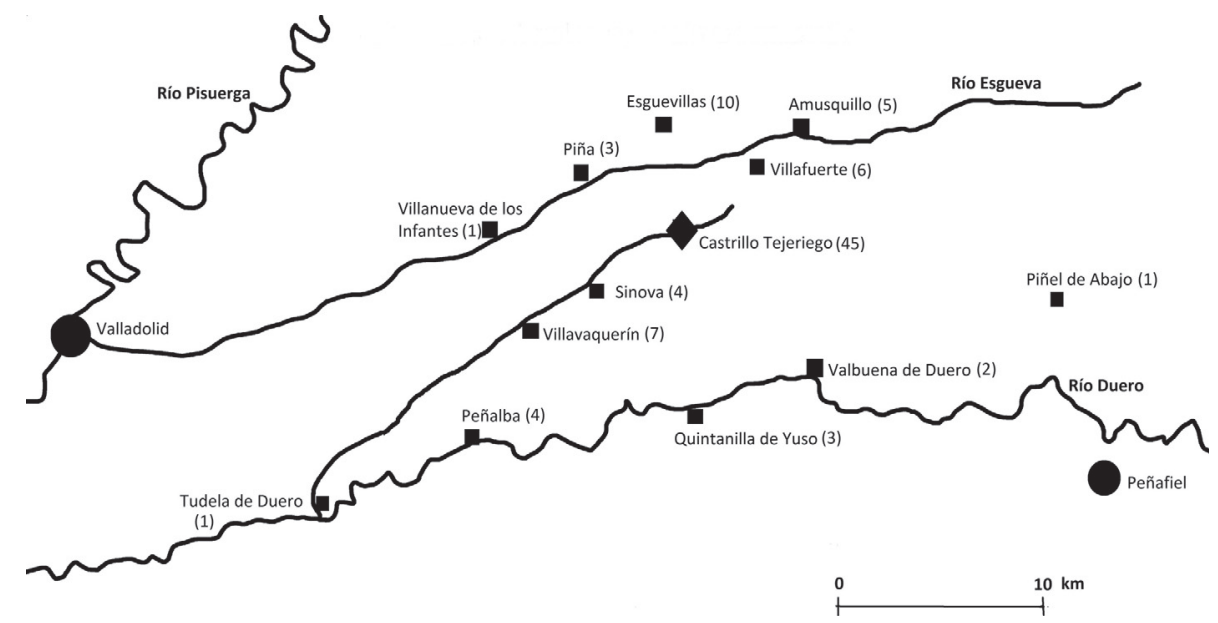

Mapa 1: Origen y número de deudores

\subsection{El impago de la deuda}

No contamos con datos fiables para conocer qué deudas fueron pagadas a tiempo, cuántas se renegociaron o tuvieron que ejecutarse en los bienes del deudor o fiador. El notario solo canceló 29 de los 67 registros de deuda (43\%), pero no consta la fecha en que lo hizo ni qué sucedió con el resto. Por otra parte, la cancelación puede depender del acreedor. Así, entre las diez deudas debidas a Domingo Martín, cura, la única cancelada fue la que prestó conjuntamente con Ruy Pérez, el hijo del escribano Gonzalo Pérez. Por contra figuran canceladas el $71 \%$ de las deudas a Ruy Pérez y el 58\% de Benito Sánchez.

En tres ocasiones el acreedor reclamó el impago de la deuda ante los alcaldes del lugar, pidiendo que se vendiesen los bienes del deudor. En una, los alcaldes se negaron a ejecutar la deuda alegando que el deudor no era vecino del lugar y, por tanto, no les correspondía hacerlo. En otra, exigieron al acreedor que presentase la carta del escribano público y pusiese sus propios bienes como garantía de la veracidad de la demanda. Solo en la tercera procedieron a la venta de bienes muebles y raíces del deudor para pagar la deuda y los gastos originados ${ }^{31}$. En este último caso, a los $30 \mathrm{mrs}$. de la deuda se

\footnotetext{
${ }^{31}$ La dificultad para ejecutar la deuda la documenta también Soldevila 2008, pp. 165-172.
} 
añadieron otros cinco por la carta de deuda, cinco gastados en ir a Valladolid a por dicha carta, cuatro para los alcaldes y cinco más para el escribano por la nueva carta, lo que elevó la suma a 49 , es decir, un $63 \%$.

Los alcaldes podían también decretar la prisión por deudas, como hicieron con Pedro Fernández Saquero, lo que llevó a su mujer a obligar sus propios bienes al pago. En otra ocasión, un deudor fue excomulgado por no pagar lo que debía a un judío de Peñafiel, pero ello es excepcional y se explica porque había una sentencia de un arcipreste ordenando el pago, sentencia que no se había cumplido.

El impago por el deudor obligaba a los fiadores, quienes luego podían resarcirse en los bienes del primero. Así, los dos fiadores de García Pérez y su mujer, que habían tenido que pagar la deuda en su lugar, hicieron vender tres tierras del matrimonio por valor de $50 \mathrm{mrs}$., alegando el poder que les otorgaba la carta de fiadura. Por otra parte, al ser muchas deudas mancomunadas, uno de los deudores podía requerir a los otros para que hiciesen frente al pago de su parte.

\subsection{La acumulación de deudas y su significado}

La tercera parte de los deudores vecinos de Castrillo Tejeriego figuran como deudores en varias notas. Las razones son varias. En primer lugar, la práctica de algunos acreedores de prestar cereal hasta el mes de mayo, con la finalidad de fijar el precio en dicho mes, encadenaba deudas. Así, en febrero de 1334 Benito Sánchez vendió a crédito una carga de trigo y otra de cebada a Juan Fernández, clérigo, y a otros dos vecinos de Villavaquerín; el plazo es ilegible. A fines de mayo los tres deudores se obligaban a pagarle $125 \mathrm{mrs}$. por Santa María de Agosto, en Valladolid, cantidad que coincide con el valor dado a esas dos cargas de cereal ${ }^{32}$.

En otros casos, la sucesión de créditos responde a su impago y a la insolvencia de deudores como Pedro Fernández Saquero. El 12 junio de 1334 contrajo una deuda, junto con Alfonso Pérez herrero, de 33 mrs. con el cura Domingo Martín, a devolver en Santa María de Agosto. El 25 de agosto tuvo que renegociar el préstamo, comprometiéndose a pagar $50 \mathrm{mrs}$. en dos plazos por San Miguel y San Martín. No lo hizo, ya que a finales de noviembre los alcaldes del lugar le dieron por preso a causa de dicha deuda, junto con

\footnotetext{
${ }^{32}$ Casos similares se ven en la adquisición de dos cargas de centeno en febrero a pagar en mayo, cuando se fija una deuda de 120 mrs. para San Antolín. Lo mismo sucede con un préstamo de tres cargas y media de cebada a pagar en mayo, cuando se contrae un nuevo préstamo por 192,5 mrs. a pagar en agosto, lo que supone $55 \mathrm{mrs}$. la carga.
} 
Domingo Pérez y Romero, tal vez sus fiadores o mancomunados. Entonces su mujer, doña Mayor, obligó sus bienes al pago de esa cantidad al referido Domingo Pérez antes de Navidad, porque el dicho mío marido non tiene agora de qué pagar.

La situación de Diego Martínez, hijo de Juan Martín el Prior, no era mejor. En junio de 1334, Fernand Martínez le reclamó ante los alcaldes $30 \mathrm{mrs}$. de una deuda impagada, más los gastos; los alcaldes vendieron medio solar y una carga de centeno de los bienes del deudor. En febrero de 1335 Diego vendió una tierra por $50 \mathrm{mrs}$. y una oveja a Domingo Martín clérigo, de quien recibió además una carga de trigo en préstamo. Tampoco pudo pagar las contribuciones en las derramas del concejo, por lo que los recaudadores, en tres ocasiones (junio y septiembre de 1334 y marzo de 1335), vendieron pequeñas parcelas de tierra de su propiedad por cantidades bastante reducidas, de entre 3 y 9 mrs. Un solar suyo fue comprado por Alfonso Fernández de Tudela, marido de doña María, la madre o hermana de Diego, y uno de los propietarios de bueyes en el lugar. La relación entre ambos era mala, pues Diego le había denunciado ante los alcaldes por agredir a doña María (marzo de 1334). Alfonso tuvo que presentar fiadores por $100 \mathrm{mrs}$. para mantener su libertad hasta el juicio y, cuando este se produjo, doña María rechazó que pusiesen tregua entre ella y su marido. Ello explica que Alfonso no le prestase ayuda económica.

Las deudas podían derivar de las inversiones realizadas para la compra de heredades. Juan Rodríguez, clérigo de Quintanilla, compró a su hermano Sancho su herencia paterna en Castrillo Tejeriego por 90 mrs., reconociendo a continuación una deuda de $30 \mathrm{mrs}$. con el vendedor. De forma similar, Domingo Fijo compró parte de un solar por $60 \mathrm{mrs}$. y una oveja el 8 de mayo de 1334; el día 30 de ese mes tomaba prestados 60 mrs. de Benito Sánchez, lo que lleva a pensar que pagó con dicho dinero o, tal vez, con una carga de cereal, ya que es el precio a que entonces se cotizaba. Otros dos deudores habían comprado tierras poco antes de pedir prestado dinero o cereal.

La acumulación de deudas se da también entre vecinos solventes. Don Tello, hijo de don Martín el zapatero, figura nada menos que en cinco registros relacionados con deudas. Cuatro se contrajeron en los primeros meses de 1334, durante la carestía. El 30 de enero, junto con Juan Martín hijo de la Freira, recibió 36 mrs. de Benito Sánchez, a pagar el 24 de junio. El 12 de mayo compró a Domingo Martín cura, una carga de cebada por 30 mrs., que se comprometió a pagar en Santa María de Agosto, ya fuese en dinero, ya en cereal. El precio de la venta era muy ventajoso, pues por entonces la carga de cebada se vendía a $60 \mathrm{mrs}$. en la comarca, lo que, junto con la forma de pago (dinero o cereal), muestra un claro trato de favor por parte del acreedor. El 30 de mayo reconoció una nueva deuda con Benito Sánchez, tal vez una renova- 
ción de la anterior, en esta ocasión por 75 mrs., que pagaría en Santa María de Agosto en Valladolid, ya en dinero, ya en cereal. Por último, el 19 de junio, junto con otros dos vecinos, reconoció deber al alcaide del castillo dos cargas y media de cebada que, de nuevo, se comprometía a pagar por Santa María de Agosto. Como ya he señalado, tal vez se trate del aplazamiento de un tributo más que de un préstamo en especie o dinero. Don Tello era uno de los propietarios de bueyes del lugar, y en noviembre, junto con otros dos vecinos, tomó en arrendamiento de Nicolás Martínez una heredad por tres años, ocasión en que recibieron de Nicolás 80 mrs. a devolver en uno y tres años. En este caso, las repetidas deudas, sus cantidades y condiciones, muestran la falta de liquidez de don Tello, pero, también, su solvencia. Una conclusión similar podríamos sacar de las contraídas por Juan Martín hijo de la Freira o por Domingo Juan hijo de Domingo Juan, ambos propietarios de bueyes y tierras, que comparten deudas entre sí y con don Tello; Domingo fue además uno de los recaudadores de los tributos concejiles; Juan, uno de los tres arrendadores de la uva de la cofradía de Capelludos, y con la suficiente solvencia para ofrecer como dote de su hija tres cargas de trigo, dos tierras, una viña y un solar.

Estos ejemplos muestran la complejidad del mundo de los deudores, las diferentes situaciones tras estos reconocimientos de deuda y los diversos motivos que conducían a solicitarlas. Se trata de algo que ya ha sido puesto de relieve para otros espacios en estos mismos años ${ }^{33}$.

\section{DOS CASOS SINGULARES}

He optado por estudiar por separado el caso de un deudor, el concejo de Castrillo Tejeriego, y un acreedor, el judío don Creciente, pues ambos representan dos realidades diferentes a las antes analizadas, que pueden ilustrar el endeudamiento municipal y el crédito judío, aunque se trate de casos aislados.

\subsection{Las deudas del concejo}

El concejo de Castrillo Tejeriego aparece como deudor en varias ocasiones. Tales deudas suelen estar relacionadas con el impago de rentas y servicios reales, señoriales o eclesiásticos. El 1 junio de 1334, el alcaide del castillo de Castrillo Tejeriego reclamaba al concejo el pago del pecho fforero

${ }^{33}$ Furió 1998, p. 165-167; García 2002, pp. 44-50; Soldevila 2008, pp. 147-156. 
debido por Pentecostés (15 de mayo); cuando el concejo intentó ganar tiempo pidiendo una carta del rey en que ordenase tal pago, el alcaide mandó cerrar las puertas del lugar. En el vuelto del mismo folio se recoge una lista de 27 bueyes, valorados en 1.235 mrs., que se habían llevado del lugar García López de Torquemada, un noble de la comarca ${ }^{34}$, y Sancho Ruiz de Villángomez. Es posible que fuese el alcaide quien los tomase como prenda para el pago, pero no hay que descartar que hubiesen sido robados durante la expedición de los partidarios de don Juan Núñez de Lara.

Dos semanas después (17 de junio), el concejo daba poder a dos vecinos para ir a Valladolid a negociar un préstamo de cuatro cargas de cereal (tres de centeno y una de cebada), que debían a Benito Sánchez, su vecino (al parecer este se las había entregado a un canónigo de Palencia en nombre del concejo, probablemente por el pago de las tercias pontificias) ${ }^{35}$. Debían llegar a un acuerdo tanto sobre la deuda principal como sobre las penas, si las él quisiere leuar, y conseguir un nuevo préstamo del propio Benito o de otro cualquiera, el que mejor condiciones ofreciese. A mediados de diciembre, el concejo se obligaba al pago de 800 mrs. a su señor, el obispo de Osma, en dos plazos: Carnestolendas (antes del 8 de febrero) y Santa María de Agosto. El concejo declaraba que el obispo se lo había prestado por nos ffazer amor, sin especificar si se trataba del impago de una renta señorial $\mathrm{u}$ otro motivo.

De hecho, las reclamaciones se acumulaban: el 20 de enero de 1335 nombró cinco personeros (procuradores) para que negociasen con los recaudadores de las tercias reales, que les emplazaban para su pago. Este asunto todavía no se había resuelto a principios de abril, cuando se nombraron nuevos procuradores, entre ellos Benito Sánchez, lo que sugiere que el concejo planeaba sufragarlas con un nuevo préstamo de su vecino. Este mismo día el concejo daba su poder a otros cinco vecinos para ir a Valladolid a tratar con el obispo de Osma sobre los 1.200 mrs. que reclamaba Gonzalo Ruiz de la Guarda, de nuevo sin que se precise el concepto.

Al margen de los motivos de estas deudas, el concejo tenía que negociar préstamos a corto plazo para su pago, recurriendo al principal prestamista de la localidad, Benito Sánchez, pero también a su señor, el obispo de Osma, o a los vecinos de Valladolid, el principal centro económico y mercantil de su comarca.

\footnotetext{
${ }^{34}$ Estepa 2003, vol. I, pp. 406-408.

${ }^{35}$ El canónigo, llamado Ardón u Ordón Álvarez, figura en el Cuaderno de préstamos del obispado de Palencia de 1350 (Archivo de la Catedral de Palencia, Archivo Capitular, n. ${ }^{\circ} 2289$, f. $23 \mathrm{v}$ ) como principal prestamero en Castrillo Tejeriego; le correspondía el $80 \%$ de la tercia pontificia en el lugar, estimada ese año en 80 cargas de pan y 28 mrs.
} 


\subsection{El crédito judío}

Los estudios sobre la Corona de Aragón han destacado el papel entre el campesinado del crédito judío, así como que utilizaban de modo preferente ciertos escribanos ${ }^{36}$. En Castrillo Tejeriego no había comunidad judía, estando las aljamas más cercanas en Valladolid y Peñafiel ${ }^{37}$. Esta distancia puede explicar que no haya acreedores judíos en los reconocimientos de deuda. Si bien, hay noticia indirecta de uno de estos préstamos. Domingo Rodríguez, que había pedido un préstamo a don Creciente, judío de Peñafiel, falleció antes de pagarlo. Sus hijos sometieron el asunto al arcipreste, probablemente el de Peñafiel, que falló a favor de don Creciente; como no pagaron, excomulgó a uno de ellos, Ruy Pérez. El excomulgado requirió a sus hermanos, dos de ellos clérigos, para que pagasen su parte, a lo que estos se negaron, alegando que no tenían parte en los bienes de su padre. Es probable que Domingo fuese vecino o morador de Quintanilla de Yuso, aldea de Peñafiel, no de Castrillo, dado que varios de sus hijos eran propietarios y vecinos allí; esto explicaría que acudiese a endeudarse a Peñafiel.

El impago parece derivar de las disputas entre los herederos y de un desacuerdo en lo concerniente a la deuda más que de la insolvencia de los hermanos. En los meses siguientes, el referido Ruy Pérez, morador en Castrillo Tejeriego, arrendó de su hermano Pedro Rodríguez, clérigo, su parte de la herencia en el lugar, a la vez que reconocía deberle $40 \mathrm{mrs}$. Un tercer hermano, Juan, que también era clérigo, compraba la parte en la herencia a un cuarto, Sancho, en este caso por 90 mrs., de los que 30 eran reconocidos como deuda. Las propiedades en dos lugares y la condición de clérigos de dos hermanos muestran que no se trata de una familia pobre, sino que tenía una posición bien asentada, aunque el valor de la herencia en Castrillo Tejeriego no permita considerarles labradores ricos.

\section{CONCLUSIONES}

El registro notarial de Castrillo Tejeriego abre una nueva ventana al conocimiento del crédito en la Castilla del siglo XIV. Esta ventana deja ver una parte de la realidad, la del mundo campesino, mal conocida en este espa-

${ }^{36}$ Castán 1983, pp. 67-76; Furió 1998, pp. 153-159; Fernández 1998; Soldevila 2008, pp. 130-137.

${ }^{37}$ En el Ordenamiento de Toledo de 1291 figuran siete aljamas en el obispado de Palencia. Valladolid es la segunda en importancia, mientras que la contribución de Peñafiel no alcanza la décima parte de la de Valladolid (Hernández 1993, vol. I, pp. 142, 146). 
cio. No obstante hubo otras realidades como el crédito judío, el crédito señorial, el crédito urbano, artesanal y mercantil, que escapan a esta fuente, pero no deben ser ignoradas, como se deduce de su comparación con espacios mejor documentados (Valencia, Cataluña). El crédito revelado por este registro es un crédito entre cristianos, aunque haya una referencia a un acreedor judío. La distancia a las principales villas de la comarca (Valladolid y Peñafiel), unos $30 \mathrm{~km}$., permitió el desarrollo de un crédito local y supralocal (los moradores de su entorno inmediato, unos diez kilómetros, acuden allí para conseguir préstamos de los principales acreedores) conectado con estas villas y con los lugares de su entorno: el principal acreedor deambula entre Castrillo Tejeriego y Valladolid, los mercados de Valladolid y Peñafiel fijan el precio del cereal a la hora de devolver los préstamos, algunos vecinos acuden a estas villas para prestar o endeudarse a pesar del coste que suponía (uno de ellos valoró el viaje en $5 \mathrm{mrs}$.).

La mayor parte de las deudas estudiadas parecen derivar de ventas a crédito de alimentos, tanto cereal como carne de cerdo. Ello tiene un componente coyuntural, la gran carestía del invierno y primavera de 1334, pero continuó después. La compra de tierras, solares o paños, los arrendamientos o el pago de tributos fueron otros motivos que llevaron a contraer deudas. En general, el plazo para su pago era de unos pocos meses, condicionado por la nueva cosecha de cereal o la posibilidad de vender el vino o el ganado. El término de un año solo se superó cuando el préstamo estaba vinculado a un arrendamiento de tierras o a la entrega del usufructo de una heredad o renta como garantía del pago e interés (commodatum).

Las motivaciones de acreedores y deudores son muy variadas, más allá de la búsqueda de beneficio o la necesidad. Los principales acreedores están vinculados al comercio de cereal o de productos ganaderos, pero también hay señores o nobles que buscan beneficios o aplazan cobros de tributos, clérigos que venden o prestan los frutos de sus rentas o las de su iglesia con condiciones diferentes a unos vecinos u otros, familiares que prestan a sus allegados... Los principales prestamistas invierten fuertes sumas en la compra de tierras, tanto a sus deudores como a otros campesinos, lo que no implica que prestasen para hacerse con tales tierras. El mundo de los deudores era igualmente heterogéneo: campesinos propietarios de tierras y bueyes, otros que no consta tuviesen heredades, clérigos, el concejo y, tal vez, algún noble local.

Formalmente, domina la forma más sencilla de crédito, el mutuum, con una presencia muy secundaria del commodatum. No se documenta la comanda, aunque se conociese en Castilla, ni formas derivadas de compañías mercantiles, más propias del ámbito urbano. Tampoco aparecen los censos consignativos que, como es bien sabido, en Castilla surgieron a fines del siglo XV. A pesar de esta importante diferencia, el crédito había penetrado con 
fuerza en estos pueblos castellanos, con la misma complejidad de relaciones y necesidades de acreedores y deudores que en el mundo rural de Valencia o Cataluña. Era una parte fundamental de la actividad económica de los campesinos, ligado a la compraventa de alimentos o tierras, a las herencias, el pago de impuestos, etc.

\section{BIBLIOGRAFÍA CITADA}

Borrero Fernández, María de las Mercedes (1986), Efectos del cambio económico en el ámbito rural: los sistemas de crédito en el campo sevillano (fines del siglo XV y principios del XVI), "En la España medieval" 8, pp. 219-244.

Borrero Fernández, María de las Mercedes (2006), Crédito y mundo rural en Andalucía. Préstamos y endeudamientos en tiempos de los Reyes Católicos, en García Fernández, Manuel; González Sánchez, Carlos Alberto (eds.), Andalucía y Granada en tiempos de los Reyes Católicos, Sevilla, Universidad de Sevilla - Universidad de Granada, vol. I, pp. 25-40.

Carrasco Pérez, Juan (2008), Crédito y fiscalidad en el reino de Navarra bajo el gobierno de la casa de Francia (1280-1328), "Príncipe de Viana" 243, pp. 37-68.

Carvajal, David (2013), Crédito privado y deuda en Castilla (1480-1521), Valladolid, Universidad de Valladolid (tesis doctoral), https://www. educacion.gob.es/teseo/mostrarRef.do?ref=1065768 [consulta: 05/ 11/2019].

Casado, Hilario (1987), Señores, mercaderes y campesinos. La comarca de Burgos a fines de la Edad Media, Valladolid, Junta de Castilla y León.

Castán Lanaspa, Guillermo (1983), Créditos, deudas y pagos en el área rural castellano-leonesa (siglos XI-XIV), "Studia Historica. Historia Medieval" 1, pp. 67-85.

Catalán, Diego (ed.) (1977), Gran Crónica de Alfonso XI. Edición crítica, Madrid, Gredos.

Covarrubias Horozco, Sebastián de (1611), Tesoro de la lengua castellana o española, Madrid, Luis Sánchez.

Estepa Díez, Carlos (2003), Las behetrías castellanas, Valladolid, Junta de Castilla y León.

Fernández Cuadrench, Jordi (1998), Crédit juif et solidarité villageoise dans les campagnes barcelonaises au XIII ${ }^{e}$ siècle, en Berthe, Maurice (ed.), Endettement paysan et crédit rural dans l'Europe médiévale et moderne, Toulouse, Presses Universitaires du Mirail, pp. 169-183. 
Férotin, Marius (1897), Recueil des chartes de l'abbaye de Silos, París, Imprimerie nationale.

Furió, Antoni (1998), Endettement paysan et crédit dans la Péninsule Ibérique au bas Moyen Âge, en Berthe, Maurice (ed.), Endettement paysan et crédit rural dans l'Europe médiévale et moderne, Toulouse, Presses Universitaires du Mirail, pp. 139-167.

Furió, Antoni (2011), Disettes et famines en temps de croissance. Une révision de la 'crise de 1300': le royaume de Valence dans la première moitié du XIV siècle, en Bourin, Monique; Drendel, John; Menant, François (eds.), Les disettes dans la conjocture de 1300 en Méditerranée occidentale, Roma, École française de Rome, pp. 343-416.

García Marsilla, Juan Vicente (2002), Vivir a crédito en la Valencia medieval. De los orígenes del sistema censal al endeudamiento del municipio, Valencia, Universitat de València.

Hernández, Francisco J. (1993), Las rentas del rey. Sociedad y fisco en el reino castellano del siglo XIII, Madrid, Fundación Ramón Areces.

Ladero Quesada, Miguel Ángel (1990-1991), Crédito y comercio de dinero en la Castilla medieval, "Acta historica et archaeologica medievalia" 11-12, pp. 145-159.

Ladero Quesada, Miguel Ángel (1993), Fiscalidad y poder real en Castilla (1252-1369), Madrid, Editorial Complutense.

Ladero Quesada, Miguel Ángel (2000), Monedas y políticas monetarias en la Corona de Castilla (siglos XIII a XV), en Moneda y monedas en la Europa medieval (siglos XII-XV), Pamplona, Gobierno de Navarra, pp. 129-178.

Laliena Corbera, Carlos (2011), Développement économique, marché céréalier et disettes en Aragon et en Navarre, 1280-1340, en Bourin, Monique; Drendel, John; Menant, François (eds.), Les disettes dans la conjocture de 1300 en Méditerranée occidentale, Roma, École française de Rome, pp. 277-308.

Laliena Corbera, Carlos; Iranzo Muñío, María Teresa (2016), Mercado de crédito, deuda censal y señoríos en la corona de Aragón (siglo XV), en Laliena Corbera, Carlos; Lafuente Gómez, Mario (coords.), Consumo, comercio y transformaciones culturales en la baja Edad Media: Aragón, siglos XIV-XV, Zaragoza, Grupo de Investigación Consolidado CEMA, pp. 233-264.

Martínez Díez, Gonzalo (1981), Libro Becerro de las Behetrías. Estudio y texto crítico, León, Centro de Estudios e Investigación San Isidoro.

Ortego Rico, Pablo (2014-2015), Pedido regio y repartimientos en Castilla: aproximación a partir del ejemplo del arzobispado de Toledo (1399- 
1476), "Baetica. Estudios de Arte, Geografía e Historia" 36-37, pp. 119-156.

Pérez Celada, Julio A. (1987), Documentación del monasterio de San Zoilo de Carrión (1301-1400), Palencia, J. M. Garrido Garrido.

Reglero de la Fuente, Carlos Manuel (1995), El Poblamiento en el noreste de la Cuenca del Duero en el siglo XV, "Hispania" 190, pp. 425-493.

Reglero de la Fuente, Carlos Manuel (2011), Les disettes dans le royaume de Castille (entre 1250 y 1348), en Bourin, Monique; Drendel, John; Menant, François (eds.), Les disettes dans la conjocture de 1300 en Méditerranée occidentale, Roma, École française de Rome, pp. 309342.

Rubio Vela, Agustín (1982), A propósito del 'mal any primer'. Dificultades cerealísticas en la Corona de Aragón en los años treinta del siglo $X I V$, en Estudios dedicados a Juan Peset Aleixandre, Valencia, Universidad de Valencia, vol. III, pp. 475-487.

San Martín Payo, Jesús (1951), La más antigua Estadística de la Diócesis Palentina (a. 1345), "Publicaciones de la Institución Tello Téllez de Meneses" 7, pp. 1-120.

Sánchez Martínez, Manuel (coord.) (2007), El món del crèdit a la Barcelona medieval, Barcelona, Arxiu Històric de la Ciutat - Institut de Cultura Ajuntament de Barcelona.

Soldevila i Temporal, Xavier (2008), Crèdit i endeutament al comtat d'Empúries (1330-1335), Girona, Ajuntament de Castelló d'Empúries.

Fecha de recepción del artículo: diciembre 2019

Fecha de aceptación y versión final: marzo 2020 